\title{
University of Zagreb and Open Access Initiatives
}

\author{
Damir Boras \\ Rector \\ University of Zagreb \\ Trg maršala Tita 14, Zagreb, Croatia \\ rector@unizg.hr,dboras@ffzg.hr
}

Those who worked at universities in Croatia in the 90s, in the era before the World Wide Web, probably remember the internet application named Gopher which allowed access to hierarchically-organized text files that could be brought from university servers from all over the world to a text viewer application on a computer of a scientist, scholar or student. About 30 years ago higher education institutions relied on text-only information on the internet to communicate with the public and other scholarly institutions. The internet connection that was used by many teachers and researchers at Croatian colleges at that time was a $24 \mathrm{k}$ or $56 \mathrm{k}$ modem and a telephone line. The idea of open online access to published research papers, textbooks and teaching material was not shared even among the early adopters of internet technology at our universities. Books and journals were in paper format and either purchased or accessed through the National University Library (NSK) or specialized libraries at research institutes, colleges like the School of Medicine or the Faculty of Electrical Engineering and Computing, or small departments like Psychology or Information Science at our Faculty of Humanities and Social Sciences (traditionally known as Faculty of Philosophy).

Today, scholars, students and the public can use university web sites to access vast amounts of information about many areas of life and work at higher education institutions. Easily accessible web services like Google Scholar and Google Books complement the use of specialized libraries and online databases like Scopus, Web of Science, Ebsco or Science Direct. Electronic book readers like Kindle and tablet computers enable students to carry hundreds of books in their back-packs. Also, at any time students can use their smartphones to access college websites, university online services or e-courses from virtually any location.

It was 15 years ago that the scholars at the Massachusetts Institute of Technology (MIT) began the OpenCourseware project to fulfill the MIT's mission "to advance knowledge and educate students". In 2002 they had teaching material for 50 courses publicly available online on their website and in less than 5 years a total of 1250 MIT courses were sharing their teaching material with scholars and students all over the world.

In the area of information systems and services at the university level there is a lot of importance placed on the development, maintenance and protection of administrative, academic and research information resources. The concept of 
academic e-infrastructure is sometimes extended to the idea of e-university which contributes to university vision and mission by advancement of ICT that supports institutional processes and enables academic analytics. Most of the related ICT and e-services are commonly provided by university departments for information systems or e-infrastructure. At the University of Zagreb this role is performed by the University Computing Centre (SRCE).

The principal "customer" of a university is the student. This customer is interested in acquiring a qualification for a career after graduation. For some of them it is teaching excellence of professors that motivates them to enroll a specific college, while for others the research reputation of the institution matters as well. The various aspects of college infrastructure and campus life are often used for rankings of universities which are available to prospective students. The information about the quality of teaching at the University of Zagreb is less available to our prospective students if course descriptions and teaching materials are not placed on our university web domain. The research papers of college departments are harder to access by the students and if they cannot be found on college websites. The scientific production of researchers can more easily be found by other scholars and perhaps cited if it can be accessed directly on the open web.

The research quality and quantity of universities is annually measured and universities are ranked on lists like Academic Ranking of World Universities (ARWU) of the Shanghai University, CWTS Leiden Ranking, and QS World University Rankings. In 2015 the ranking of the University of Zagreb has slightly improved regarding its research output. However, for the last 10 years universities have also been ranked by their web presence in form of the Ranking $W e b$ or Webometrics ranking of higher education institutions. On this measure of performance of universities from all over the world, based on their web presence and impact, the University of Zagreb is currently holding the 458 position. The goals of the Webometrics ranking are to promote publication on the web and support Open Access initiatives. More importance is also placed on free and unrestricted internet access to scientific publications and other academic material, as well as to information about various activities of professors and researchers, including informal scholarly communication. Like the MIT OpenCourseware project, Webometrics ranking is intended to provide better access to scientific knowledge not only to students and researchers located in developing countries, but also to regional third parties like industry and government. Croatian universities, our academics and researchers should contribute to the Open Access and Open Educational Resources initiatives. For instance, the Senate of the University of Zagreb has supported the Croatian Declaration on Open Access. However, greater engagement of higher education institutions, researchers and teachers is needed to make the contributions of our universities more available to the society and general public. This is one important aspect of the e-university we are trying to implement. This one possible contribution of 
our higher education institutions to our society and students. By such initiatives our position among world universities may improve and our reputation enhance. The leap from Gopher application to Webometrics ranking in less than 30 years, the change from printed scholarly books and journals behind library walls to Open Access and e-university. We have an exciting academic INformation $\mathrm{Fu}$ ture of INFuture before us and we just have to be more engaged to make it happen. 